\title{
INTELECTUALES EN SOCIEDADES DEMOCRÁTICAS
}

\author{
Juan Herrero Senés \\ (University of Colorado Boulder)
}

Odile Heynders, Writers as public intellectuals: Literature, Celebrity, Democracy, Nueva York, Palgrave Macmillan, 2016, 218 pp. ISBN: 978-1-137-46764-5

Odile Heynders, profesora de estudios culturales comparados en la Universidad de Tilburg (Holanda), sintetiza en el presente libro varios años de investigación dedicados a indagar el estatus presente del intelectual en un contexto europeo transnacional. ¿Quiénes son los que están abordando los problemas y retos de este tiempo complejo y convulso, alzando su voz e implicándose en aportar su punto de vista? ¿En qué marco llevan a cabo los escritores su constitución como intelectuales? Y ¿cómo lo hacen, qué estrategias utilizan para llegar a su público?

Las respuestas de Heynders a estas preguntas se ofrecen en el texto por inducción a partir del despliegue del análisis de la labor de siete destacados intelectuales en el viejo continente, desde el ya anciano Hans Magnus Enzensberger (nacido en 1929) hasta la novelista turca Elif Shafak, que no alcanza los 50 años. Heynders ve en cada uno de los escritores tratados la ejemplificación de un tipo de intelectual, o de una forma distintiva de ejercer como tal. Al juntarlos y contrastarlos presenta una panoplia de posibilidades que desafía definiciones anticuadas del intelectual público, entendido como aquel intelectual que se implica activamente en los debates del presente y con regularidad (se) expone a una audiencia (en) sus opiniones. Heynders nos hace ver que las condiciones en que se actualiza el rol de intelectual se han modificado radicalmente en los últimos veinte años, y alude a tres cambios fundamentales: Primero, en el contexto de la globalización, ningún problema posee ya un alcance -ni un enfoque, ni una 'solución'- exclusivamente nacional, por lo que los asuntos deben ser abordados desde una 
perspectiva que intente sintetizar lo local con lo internacional y atienda especialmente a sus interrelaciones. Segundo: la percepción por parte de la opinión pública del intelectual en tanto que ciudadano visiblemente concienciado más que como autoridad hace imposible la omisión de su individualidad, su biografía y situación enunciativa particular en tanto que condicionantes de su discurso, y por tanto imposibilita que el intelectual se arrogue la expresión de opiniones objetivas y/o de alcance espacio-temporal universal. Y, en tercer lugar, los escritores no pueden ya circunscribir la expresión de sus ideas y opiniones a los canales de comunicación tradicionales o usualmente percibidos por los propios intelectuales como "apropiados" (la palabra escrita o el discurso directo frente a un auditorio), sino que deben tener en cuenta y aprovecharse tanto de formas generalmente degradadas -la televisión es el caso paradigmático- como de manera especial de las nuevas formas de comunicación en la era digital, así como de las redes sociales. De otra manera se reducen en gran medida las oportunidades de hacer llegar eficazmente el mensaje a la opinión pública. Naturalmente, Heynders es consciente de que todas estas condiciones no están exentas de problemas, al contrario, y en distintos momentos señala su ambivalencia y sus peligros.

A partir de aquí, como digo, la autora se sirve de distintas figuras públicas para, al hilo de su trayectoria intelectual, sus textos y la repercusión de sus opiniones detectar distintas estrategias de constitución y "actualización" (performance) de la posición de intelectual dentro de la sociedad, incluidas aquellas se alejan de las más reconocibles (o, nuevamente, "apropiadas" dentro de una visión más tradicional). Encontramos aquí, por ejemplo: el uso extendido par parte de un mismo autor de distintos géneros literarios -ficciones, autobiografías, memorias, ensayos, poemarios-; la constitución de lo que Heynders Ilama una "voz privada pública", en la que el intelectual parte de su propia experiencia vital concreta (por ejemplo como exiliado de un país que ya no existe, en el caso de las escritoras de la ex Yugoeslavia Slavenka Drakulic y Duvranka Ugresic), YES entendida de algún modo como ejemplarizante, para estimular a los otros a pensar en su propia responsabilidad; la aplicación del humor -en sus variadas formas, sea ironía, sátira o burla- como modo enunciativo frente a problemas de primer orden (así el intelectual germano-egipcio Hamed Abdel-Samad, que como Enzersberger y Ayaan Hirsi Ali han encontrado en la televisión un eficaz instrumento de expresión). Bernard-Henry Lévy ejemplifica el uso de técnicas del mundo de los famosos -personalismo, exposición de la vida privada, 
anulación de la separación entre alta y baja cultura, actuación- como modo de vinculación con la audiencia, los belgas David van Reybrouck y Geert van Istendael publican manifiestos y construyen plataformas cívicas desde las cuales cuestionan la validez del sistema democrático actual y la eficacia de la Unión Europea. Y Elif Shafak amplifica su voz denunciadora del régimen de Erdogan en novelas comerciales, así como sus cuentas de Pinterest o Twitter.

En conjunto, el libro ofrece una sólida aproximación, instrumentos de clasificación analítica e interesantísimas perspectivas para el estudio de las nuevas formas de constitución del intelectual público en la contemporaneidad, y consigue con elegancia hacer patente que deberíamos cambiar nuestra en muchos aspectos anticuada imagen del intelectual para hacer justicia a la profusión, variedad y complejidad con que los escritores de hoy hacen Ilegar sus mensajes a una audiencia continental cada vez más perdida, enfadada y acongojada por la encrucijada en que se encuentra. El libro es claro, ordenado y diáfano en su lectura, utiliza con inteligencia y sin apabullamiento la enorme bibliografía existente sobre la figura del intelectual y tiene la virtud añadida de percibirse a ojos del lector, a pesar de su emplazamiento académico, como un texto muy actual, pues Heynders alude a eventos muy recientes y debates candentes.

Dicho todo esto, en mi opinión pueden hacerse al volumen dos reproches fundamentales: el primero es que, dentro de un libro de aliento europeísta, Heynders se centra casi exclusivamente en autores del norte del continente, particularmente en la órbita germánica (no en términos de nacimiento, claro, sino de ubicación diríamos profesional), dejando totalmente de lado a los países del arco mediterráneo. En ningún momento se alude a la labor -a la existenciade intelectuales públicos portugueses, italianos, españoles o griegos, ni siquiera en términos de descripción general del contexto europeo. Con ello Heynders, quiéralo o no, evoca en las páginas de su libro los prejuicios transnacionales de nuestros colegas del norte de Europa recientemente voceados, con estentóreo ruido, por otro holandés, el presidente del Eurogrupo Jeroen Dijsselbloem. Junto a eso y claro, en consonancia, los temas de orden político-social que afectan a Europa y en los que se centra la autora están abordados a partir de un eje de visión este-oeste, esto es, observando cómo en Alemania y los países bajos se gestionan los asuntos, tensiones, miedos y ansiedades generados al calor de la situación en los países del este de Europa, fundamentalmente Turquía y las repúblicas de la ex Yugoslavia. De este modo nuevamente se obliteran las oportunidades interpretativas proporcionadas por la perspectiva 
de un eje norte-sur. Prueba de ello es que entre las páginas no se encuentran referencias, por ejemplo, al asunto de la (desastrosa) gestión por parte de la Unión Europa de la inmigración ilegal y la consecuente tragedia de los refugiados en la cuenca mediterránea. Heynders aparta la vista del problema como lo hace la propia Unión Europea.

El segundo reproche al libro es que me parece que Heynders toma una posición demasiado aséptica. Nunca expresa sus opiniones no ya ante los temas tratados por parte de los autores analizados (el proyecto y futuro de la unión europea, la inmigración, el multiculturalismo, la democracia y el populismo, la creciente sombra del islamismo sobre el continente), sino ante las prácticas de esos mismos autores. Parece defender que todas las estrategias aludidas más arriba son, digámoslo así, decisiones autorales no cuestionables en la medida en que buscan reconectar con el público y por tanto reactivar la capacidad del intelectual para incidir en la opinión pública. Creo que el libro se hubiera beneficiado de un tono menos neutral que las comentara, criticara y avalorara, quizá incidiendo más de lo que lo hace en cómo la opinión pública, u otros intelectuales han reaccionado ante ellas. En ese sentido, Heynders renuncia a una voz propia para refugiarse en una enunciación académica presentativa que choca especialmente en el caso de un libro como este.

Todo esto, claro, está ligado a la posición que la propia autora ocupa en el contexto que analiza, y que puede entenderse como consecuencias (o expectativas o incluso "exigencias") de ello, pero de algún modo contrasta negativamente con la intensidad con que la autora ha alabado dos aspectos básicos del intelectual: la implicación pública y la expresión de sus propios puntos de vista. Junto a su ubicación germanocéntrica, la asepsia, la frialdad incluso en ciertos casos acaban produciendo la sensación-por lo menos en este lector ignorante de los procederes de la academia neerlandesa- de un libro que alguna manera se acerca y se apropia de los intelectuales que aborda a la manera de un entomólogo, preocupado casi en exclusiva por la descripción y clasificación de cierta población. Fuera quedan los humanos, demasiado humanos anhelos y desvelos de aquella colonia de insectos. 